\title{
Standing laparoscopic repair of an uterine rupture in a post-partum mare
}

\author{
Mario Delcazo', Jennifer Nieth², Axel Wehrend² and Michael Röcken' \\ 1 Justus-Liebig-University, Giessen. Veterinary Faculty. Clinic for Horses. Department for Surgery \\ 2 Justus-Liebig University, Giessen, Veterinary Faculty, Clinic for Gynaecology and Obstetrics
}

\begin{abstract}
Summary: Causes of uterine rupture are well identified in the equine literature and consist mainly of persistent straining of the mare against a fetal obstruction during a dystocia. The objective of this case report was to describe diagnosis, laparoscopic repair and outcome of a uterine rupture in a post-partum mare. A 12-year-old Trakehner mare was presented to the Surgery Department of the Clinic for Horses of the Justus-Liebig-University in Giessen with a uterine rupture after foaling. Standing laparoscopy and suturing of the defect using a barbed loop suture was selected as the treatment of choice. The abdomen was flushed via laparoscopy in the same intervention and no postoperative complications related to peritonitis occurred. Follow-up examination three months after the surgical treatment showed a complete healing of the uterine mucosa. Minimally invasive surgical repair of a uterine rupture in the standing mare was technically feasible and it was related to an excellent outcome in this case.
\end{abstract}

Keywords: uterus, rupture, tear, uterine, laparoscopy, mare, minimally invasive

Citation: Delcazo M., Nieth J., Wehrend A., Röcken M. (2020). Standing laparoscopic repair of an uterine rupture in a post-partum mare. Pferdeheilkunde 36, 299-305; DOI 10.21836/PEM20200402

Correspondence: Mario Delcazo, Justus-Liebig-University, Giessen, Clinic for Horses, Department of Equine Surgery, Frankfurter Str. 108, 35392 Giessen, Germany; mario.delcazo-franco@vetmed.uni-giessen.de

Submitted: March 4, 2020 | Accepted: May 18, 2020

\section{Introduction}

Causes of uterine rupture are well identified in the equine literature and consist mainly of persistent straining of the mare against a fetal obstruction during a dystocia. These tears are usually located in the uterine body and occur when an extremity pushes through, or after blunt trauma to the uterine wall (Dascanio et al. 1993, Woodie 2019). Alternatively, tears can be induced iatrogenically by an aggressive obstetric intervention or secondary to a fetotomy (Turner 2007). These lesions can also be sustained as part of a normal delivery. In these cases, tears are generally located towards the tip of the gravid horn and are probably associated with fetal movements during labour stages I and II (Frazer 2003). Very rarely, tears are manifested pre-partum with hydramnios (Honnas et al. 1988) or uterine torsion (Wheat and Meagher 1972, Perkins et al. 1992).

Unspecific clinical signs, consisting of depression, fever, mild abdominal discomfort and tachycardia, history and ultrasonographically excessive peritoneal fluid point strongly to a diagnosis of uterine tear. Further diagnostics, such as rectal exam, vaginal examination and peritoneal fluid cytology should be performed as part of the evaluation (Woodie 2019). Depending on the defect's localisation, hysteroscopy is not always a necessary examination procedure for the diagnoses of uterine laceration. Nevertheless, it might be a helpful diagnostic tool in some cases to detect these tears located in the tips of the uterine horns. The use of hysteroscopy to diagnose a chronic uterine tear has been reported (McNally et al. 2012).
Both conservative and surgical treatment may be effective (Hassel and Ragle 1994, Javsicas et al. 2010). However, post partum uterine rupture is frequently followed by septic peritonitis due to direct seeding of the abdomen from intrauterine bacteria through the tear (McNally et al. 2012). For this reason, surgical repair is still recommended as the treatment of choice for preservation of the mare's life and breeding soundness.

A solely laparoscopic approach in the standing horse has been recently reported in two mares (Diekstall et al. 2018) using extracorporeal knots or barbed sutures. Likewise, a minimally invasive approach was selected in this case because of the location of the lesion and to eliminate the anaesthetic risk. In this report, the diagnosis and the surgical treatment via standing laparoscopy using a barbed loop suture to resolve a uterine rupture are described. Moreover, the surgical technique included a laparoscopic flushing of the abdomen as part of the treatment for peritonitis, as mentioned by Diekstall et al. (2018).

\section{Clinical Report}

A 12-year-old Trakehner maiden mare was presented approximately three hours after parturition in the clinic for Gynaecology and Obstetrics of the Justus-Liebig-University in Giessen with a suspected laceration of the uterus based on the evaluation of the referring veterinarian. According to the clinical 
history, the expulsion was shortly interrupted by the fact that, initially, only one fetal hoof could be seen in the rima vulvae. When the referred veterinarian started a conservative delivery, both fetal hoofs could be reached. After the foal's delivery and the expulsion of the fetal membranes, a laceration of the uterus was diagnosed by a transvaginal examination. The mare was treated with a tetanus antitoxin and gentamicin and was transferred to the clinic.

Upon admission, general physical examination revealed a mild tachycardia (48 beats/min) and a mild hyperthermia $\left(38.2^{\circ} \mathrm{C}\right)$. Haematology revealed a mild neutrophilia $\left(8.52 \times 10^{9}\right.$ cells $/ \mathrm{L}$; reference range: $2.2-8.1 \times 10^{9}$ cells $/ L$, Southwood 2013). Transrectal examination was consistent with an oedematous folded structure in the caudal uterus, slightly displaced to the left. The vulva was mildly swollen. Transvaginal examination did not reveal any evidence of traumata in the vestibulum or vagina and the cervix was still widely opened. Furthermore, transvaginal palpation of the uterus confirmed a uterus full-thickness laceration of approximately $8 \mathrm{~cm}$ length, localized cranially to the cervix at $11 \mathrm{o}^{\prime}$ clock position. There was no evidence of retained fetal membranes, acute bleeding or any excessive fluid accumulation in the uterus. Transabdominal ultrasonography excluded the presence of free fluid in the abdomen. The udder was bulging and colostrum could be milked. The foal appeared healthy, the maturity level and size compared to the mare were considered normal. Although the foal was fed with colostrum, it developed a failure of passive transfer, so the administration of plasma transfusions was needed. As the uterus lesion was located dorsally, a laparoscopy in the standing sedated patient was selected. Therapeutically, it received amoxicillin $(10 \mathrm{mg} / \mathrm{kg}$ bwt IV), flunixin-meglumine $(1.1 \mathrm{mg} / \mathrm{kg}$ bwt IV) and oxytocine (1.5 I.U s.c). Furthermore, she received istotonic saline in a maintenance doses via infusion before and during surgery.

\section{Surgical technique}

To repair the uterine lesion and to avoid potential peritonitis, standing laparoscopy was selected and performed the same day approximately 6 hours after admission, so feed could not be withheld for a longer time prior to the intervention. Gentamicin $(6.6 \mathrm{mg} / \mathrm{kg}$ bwt intravenously [IV]), amoxicillin (10 mg/ $\mathrm{kg} \mathrm{bwt} \mathrm{IV)} \mathrm{and} \mathrm{flunixin} \mathrm{meglumine} \mathrm{(1.1} \mathrm{mg/kg} \mathrm{bwt} \mathrm{IV)} \mathrm{were} \mathrm{ad-}$ ministered preoperatively. The horse was restrained in stocks and sedated with an initial bolus of detomidine $(0.01 \mathrm{mg} / \mathrm{kg}$ bwt IV) and butorphanol $(0.02 \mathrm{mg} / \mathrm{kg}$ bwt IV). Sedation was maintained with supplementary boli of detomidine $(2 \mu \mathrm{g} / \mathrm{kg}$ bwt IV) and butorphanol $(2 \mu \mathrm{g} / \mathrm{kg}$ bwt IV) to effect. Transrectal examination was performed to confirm that there were no intestines located at the site of the laparoscopic portals. In order to avoid loosening of intraabdominal pressure while distending the abdomen with carbon dioxide during laparoscopy and to improve visualization of the region of interest, a tampon packed in a rectal glove was introducde via vagina into the area of the uterus rupture. After aseptic surgical preparation of both flanks and $\mathrm{N}$-butylscopolammonium bromide (0.03 mg/kg bwt IV, Buscopan ${ }^{\circledR}$ compositum) administration, the first laparoscopic portal was created in the left flank, midway between the ventral aspect of the tuber coxae and the $18^{\text {th }}$ rib. Next, a $57 \mathrm{~cm}$ long telescope was introduced through the trocar. The abdomen did not need to be distended with carbon dioxide, since a good visualization of the abdominal cavity was obtained. Inspection of the abdomen revealed a moderate amount of cloudy peritoneal fluid ventrally, adjacent to the urinary bladder, as well as fibrinous adhesions on the visceral serosa of the left ovary (Figure 1 and 2). Visual assessment of the uterus revealed a post-partum enlargement, which was considered physiologic, and a full-thickness dorsal midbody uterine rupture. The lesion became evident when the telescope was brought axially around the left mesovary and caudally from the ovary. The total length of the rupture was approximately $6-8 \mathrm{~cm}$. The edges of the tear were only mildly swollen and the tissue appeared viable (Figure 3). The optic portal was then placed in the $17^{\text {th }}$ intercostal space (at the level of the ventral aspect of the tuber coxae) and a second instrument portal was created in the flank $(6-8 \mathrm{~cm}$ ventrally to the first portal). The uterine defect was sutured with a single layer of continuous Lembert pattern using an unidirectional absorbable barbed loop suture USP-O (V-LOCTM Wound Clo-

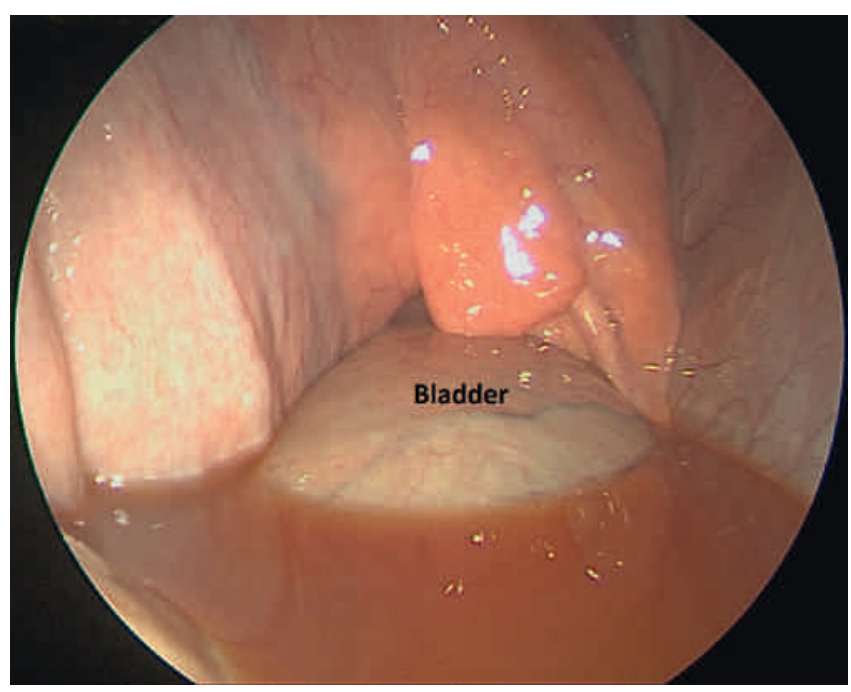

Fig. 1 Laparoscopic view of the left side of the abdominal cavity showing free peritoneal fluid. | Laparoskopisches Bild der linken Bauchhöhle, in der sich freie Flüssigkeit vorzufinden ist.

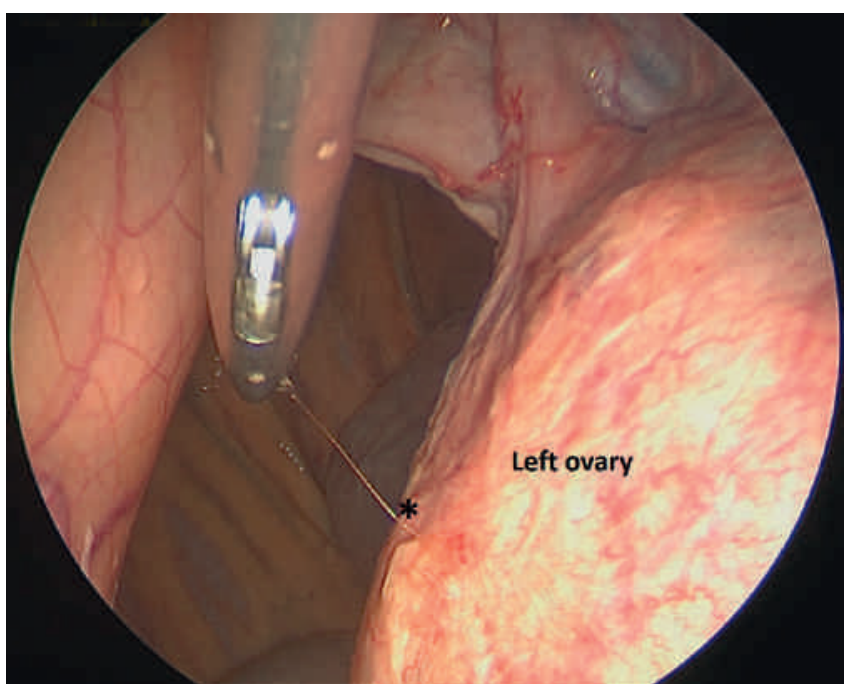

Fig. 2 Laparoscopic image illustrating the fibrinous adhesions (asterisk) on the left ovary. | Endoskopische Darstellung der fibrinösen Adhäsionen (*) auf dem linken Ovar. 
sure Device, Covidien), in a medial to lateral direction (Figure 4). Two needle holders were used for the manipulation of the

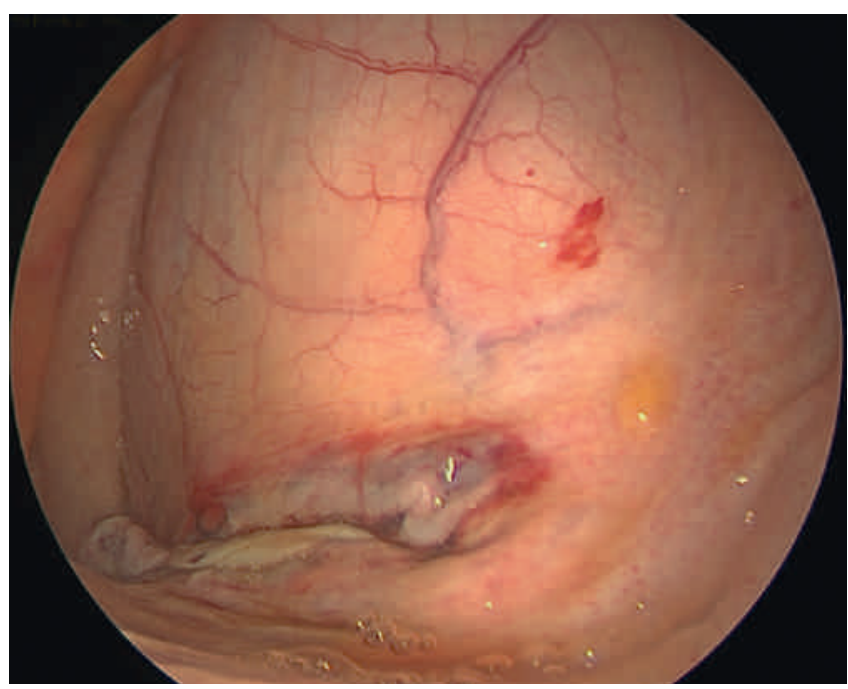

Fig. 3 Laparoscopic visualization of the uterine rupture. | Laparoskopische Visualisierung der Rupturstelle am Uterus.

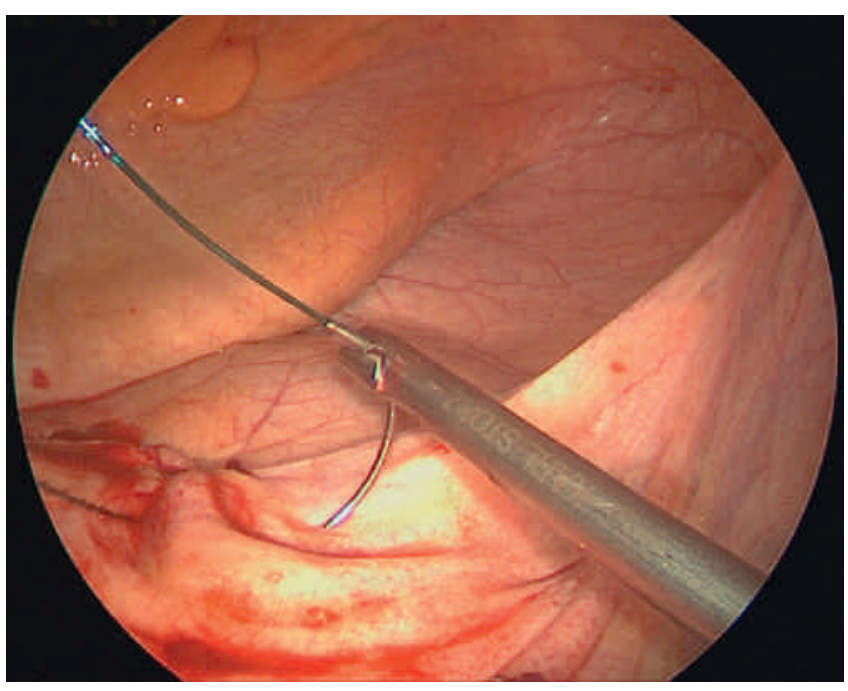

Fig. 4 View of the tear during suturing technique. Ansicht der Rupturstelle während der endoskopischen Naht

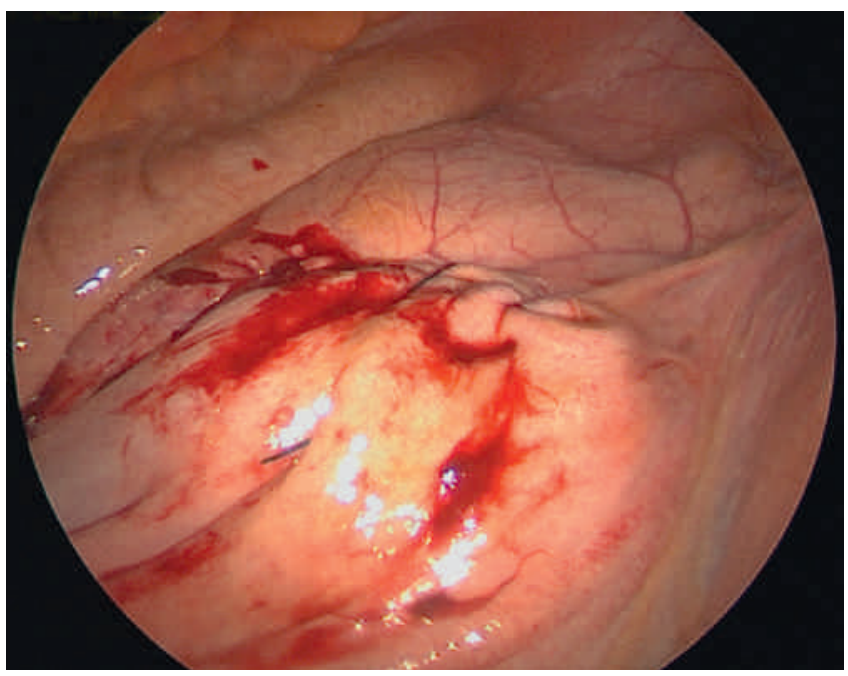

Fig. 5 View assessing the complete repair of the uterine tear. Blick auf den vollständigen Verschluss der Rupturstelle needle. Complete closure of the tear was assumed based on visual examination and transvaginal uterine digital palpation (Figure 5). Subsequently, to prevent a potential peritonitis, the abdomen was flushed with $10 \mathrm{l}$ of $0.9 \% \mathrm{NaCl}$ by means of a drain introduced in the abdomen through the lumen of the trocar from the dorsal portal of the flank. Then, the target viscera (including uterus and left ovary) were profusely flushed, guiding the drain with the forceps from the ventral portal. Afterwards, fluid aspiration from the abdomen was performed using a suction cannula attached to a vacuum system and approximately $8 \mathrm{I}$ of fluid were obtained. Because most of the volume insufflated could be aspirated back and to avoid potential problems with the foal, no Foley catheter was placed ventrally. Finally, the portals were routinely closed in two layers (external abdominal oblique muscle outer sheath and skin) using USP-1 and USP-2-0 polyglactin 910, respectively. The overall operative time was $55 \mathrm{~min}$.

\section{Post operative care}

Post-operatively, the patient was stall rested and fed with small portions of hay and mash. The mare was maintained with gentamicin $(6.6 \mathrm{mg} / \mathrm{kg}$ bwt IV, once daily) for 5 days, amoxicillin $(10 \mathrm{mg} / \mathrm{kg}$ bwt IV, every 12 hours) for 9 days and metronidazol ( $25 \mathrm{mg} / \mathrm{kg}$ bwt orally, every $12 \mathrm{~h}$ ) for 10 days. Anti-inflammatory therapy included flunixin-meglumine $(1.1 \mathrm{mg} / \mathrm{kg}$ bwt IV, once daily) for 8 days. Initially, the mare received continuous infusion of IV fluids consisting of saline and ringer lactate, meeting the standard maintenance dose of $60-75 \mathrm{~mL} / \mathrm{kg} /$ day. Moreover, the patient was treated with infusion of lidocaine at $0.05 \mathrm{mg} / \mathrm{kg} / \mathrm{min}$ for 24 hours. In order to avoid ileus, administration of metoclopramide (5 mg intramuscularly [IM], every hour) for 24 hours was also started, followed by $5 \mathrm{mg}$ (IM) every two hours in the second day. As the mare developed a mild obstipation, this treatment was continued for 5 days and tapered off. For this reason, the patient was also treated via nasogastric tube (up to 201 of water a day) and with infusion bolus of 101 ringer lactate twice daily. Initially, the puerperal involution of the uterus was checked twice daily. As increased amounts of puerperal fluid within the uterus occurred in the first two days after surgery, it was removed using a vacuum system. Moreover, low volume saline lavages were used to flush the uterus and administration of oxytocin (1.5-2 IU subcutaneously, every 8 to $12 \mathrm{~h}$ ) was started. The body temperature raised up to $38,5^{\circ} \mathrm{C}$ in the first two post-operative days, and then normalized. Three days post-operatively, the mare developed leucopenia $\left(2.8 \times 10^{9}\right.$ cells/l), mild hypoproteinaemia $(53.2 \mathrm{~g} / \mathrm{l})$ and mild hypalbuminaemia $(25.1 \mathrm{~g} / \mathrm{l})$. All laboratory parameters normalized in the following days. During the hospitalization time, the patient did not show any signs of peritonitis and the mare was discharged nine days after initial presentation.

\section{Outcome}

After discharge from hospital, uterine involution, wound healing and general convalescence were checked regularly by the referring veterinarian. The mare recovered without any complications and mild work was started approximately 4 weeks after surgery. 
Three months after discharge, the mare was presented for a follow-up examination. All vital parameters were normal and the patient was in an excellent general condition. In the rectal examination, the uterus was symmetric, with a mild tonus and its size had decreased to a physiological ingravid stage. It showed a distinct uterine oedema and the serosa was smooth. Both ovaries were of a normal size and a $4 \mathrm{~cm}$ diameter dominant follicle was present on the right ovary. Transrectal ultrasonography did not reveal any evidence of scar tissue or intrauterine or periuterine adhesions. Transvaginal examination with a Polanski speculum showed a good hymenal function. The cervix was oedemous and could be passed easily without evidence of any adhesion. During hysteroscopy, the entire extent of the uterus could be examined (from the uterine body to the tips of both uterine horns) and no adhesion or signs of inflammation could be visualized. Furthermore, neither the rupture site nor scar tissue could be detected. Endometrial cytology showed physiologic endometrial cells and mucus. An endometrial bacterial swab revealed low alpha Streptococci and $E$. coli colonization, as well as single colonies of fungus (probably related to contamination).

\section{Discussion}

This case report shows the successful laparoscopic repair in the standing mare of a full-thickness uterine rupture, thought to have occurred during foaling. As described in the literature, the interval from occurrence of the tear to diagnosis and initiation of therapy has a marked impact on the prognosis for survival (Dwyer 1993, Perkins et al. 1992, Frazer et al. 1997). In order to detect potential abnormalities, it is considered of a good management practice, to give all foaling mares a brief physical examination within $24 \mathrm{~h}$ post partum (Frazer 2003). Furthermore, it is in every veterinarian's duty of care to do an immediate postpartum transvaginal examination to detect any trauma, retained fetal membranes or even retained fetus. As puerperal diseases occur also after eutocia and without any obvious clinical signs detectable for the owner, a post parturient examination should be carried out in any mare (Schürmann et al. 2019).

In the case reported, an early and accurate diagnosis followed by appropriate and immediately surgical intervention provided an excellent prognosis for the life of the animal. In one report of post partum deaths in mares, $6.1 \%$ were attributed to uterine lacerations alone (Dwyer 1993). In another report, the survival rate of mares with uterine tears was $75 \%$, with no significant difference between medical or surgical treatment (Javsicas et al. 2010). Nevertheless, surgical repair is recommended as the best treatment for preservation of the mare's life, breeding soundness and it is related to shorter convalescence time.

Previously, surgical repair of uterine ruptures have been performed under general anaesthesia via caudal ventral midline celiotomy, a flank approach (Hassel and Ragle 1994) or hand-assisted laparoscopy (Cribb and Chenier 2012, Klohnen 2012, McNally et al. 2012). There are only two reported cases of a solely laparoscopy performed in the standing horse so far (Diekstall et al. 2018). Minimally invasive techniques are usually related to decreased post-operative morbidity and mortality and ergo a faster return to work (Lee and Hendrickson 2008).

Advantages of this technique include avoidance of risks of general anaesthesia and associated complications, as well as a reduction of total costs for the owner. However, appropriate patient selection is essential to succeed. The choice of surgical approach (standing laparoscopy vs caudal celiotomy) will depend essentially on the localization of the lesion. On one hand, laparoscopy will be indicated for ruptures located dorsally, so they are normally visualized in the standing horse. On the other hand, ventral preumbilical celiotomy will be the appropriate approach for lesions located ventrally, as these lesions may become recognizable if the horse is placed in dorsal recumbency.

In the present report, an absorbable barbed loop suture was used for the repair of the tear. Imported from human medicine, lately, this suture material has been reported in equine patients for the laparoscopic ablasion of the nephrosplenic space (Albanese et al. 2016, Gandini et al. 2017) and laparoscopic closure of the internal inguinal rings (Ragle et al. 2013). The pre-engineered loop at the end of the suture permits a reduction of the surgical time and eases the procedure, as no extraor intracorporeal nots are needed. Another advantage of the barbs is the maintenance of tissue apposition during suturing, since there is no need to maintain continuous suture tension extra abdominally. The disadvantage of this material arises from its barbed nature, so an incorrectly placed bite cannot be brought back and replaced. After identification of the uterine tear by its mildly swollen edges, the lesion was repaired with a barbed suture thus affording a short suturing time of approximately $8 \mathrm{~min}$. A common complication to avoid is the inadvertent penetration of abdominal viscera during manipulation of instruments and during trocar introduction. Although expertise of the surgeon was fundamental when manipulating the two needle holders in the axial abdomen, closure of the uterine defect was achieved without major problems and no penetration of a segment of bowel occurred. Moreover, diagnostic laparoscopy should be considered for post-partum mares with peritonitis as it allows assessment of the uterus and the gastrointestinal tract for concomitant damage (Diekstall et al. 2018). Another advantage of this technique is the option to flush the abdominal cavity and viscera from the laparoscopic portals in a dorsal to ventral fashion. As reported in the previous article, this system permits aspiration of the fluid from the abdominal cavity (Diekstall et al. 2018), avoiding the placement of an intra-abdominal drainage ventrally, which might have been problematic with the foal in this case and was therefore avoided. Following small full-thickness uterine tears, the smooth muscle surrounding the tear contracts and thus makes any communication between uterine lumen and abdominal cavity difficult to detect (McNally 2012). This fact could have avoided excessive contamination of the abdominal cavity. Although macroscopically the peritoneal fluid was consistent clearly with peritonitis, a limitation of our case report is that cytology was not performed. Thus we can only speculate on the effectivity of the laparoscopic flushing. Also, the systemic antibiotic therapy could positively influence the resolution of this condition. Even though more cases and experience with this technique are required, we hypothesise that mild cases of peritonitis in early stages can be managed with 
the implementation of this technique. In any case, the decision of placing a ventral catheter intra- or post-operatively should be taken in each individual case according to the severity of peritonitis and post-operative evolution. In contrast to the standard two-layer suture for uterine defects, a single layer was considered adequate based on visual control during transvaginal uterine digital palpation. Moreover, early surgical intervention and flushing of the abdomen was related to a good outcome in this case. In addition, we believe that early surgical intervention consisting of laparoscopy has an effect on reducing total costs for owners derived from other surgical approaches or long medical treatment.

In conclusion, treatment of a dorsal full-thickness uterine rupture was achieved via standing laparoscopy and it resulted in a very good prognosis in this mare.

\section{Conflict of interests}

The authors declare no conflict of interest related to this report.

\section{References}

Albanese V., Hanson R. R., McMaster M. A., Koehler J. W., Caldwell F. J. (2016) Use of a knotless suture for laparoscopic closure of the nephrosplenic space in eight horses. Vet. Surg. 45: 824-830; DOI 10.1111/vsu.12520

Cribb N. C., Chenier T. (2012) Uterine tears in horses. Equine Vet. Educ. 24, 444-446; DOI 10.1111/j.2042-3292.2011.00344.x

Dascanio J. J, Ball B. A., Hendrickson D. A. (1993) Uterine tear without a corresponding placental lesion in a mare. J. Am. Vet. Med. Assoc. 202, 419-420; PMID 8440635

Diekstall M., Rohde C., Rijkenhuizen A. B. M. (2018). Post-partum uterine rupture: Standing repair in three mares using a laparoscopic technique. Equine Vet. Educ. DOI 10.1111/eve.13001

Dwyer R. (1993) Post partum deaths of mares. Equine Dis. Quart. 2, 104

Fischer A. T., Phillips T. N. (1986) Surgical repair of a ruptured uterus in five mares. Equine Vet. J. 18, 153-155; DOI 10.1111/j.20423306. 1986.tb03577.x

Frazer G. S., Burba D., Paccamonti D., Blouin D., LeBlanc M. M., Embertson R., Hance S. (1997) The effects of parturition and peripartum complications on the peritoneal fluid composition of mares. Theriogenology 48, 919-931; DOI 10.1016/S0093-691X/97/00320-8

Frazer G. S. (2003) Post partum complications in the mare. Part 1: Conditions affecting the uterus. Equine Vet. Educ. 15, 36-44; DOI 10.1111/j.2042-3292.2003.tb00211.x
Gandini M., Nannarone S., Giusto G., Pepe M., Comino F., Caramello V., Gialletti R. (2017) Laparoscopic nephrosplenic space ablation with barbed suture in eight horses. J. Am. Vet. Med. Assoc. 250, 431-436; DOI 10.2460/javma.250.4.431

Hassel D. M., Ragle C. A. (1994) Laparoscopic diagnosis and conservative treatment of uterine tear in a mare. J. Am. Vet. Med. Assoc. 205, 1531-1536; PMID 7730118

Honnas C. M., Spensley M. S., Laverty S., Blanchard P. C. (1988) Hydramnios causing uterine rupture in a mare. J. Am. Vet. Med. Assoc. 193, 334-336

Javsicas L. H., Giguère S., Freeman D. E., Rodgerson D. H., Slovis N. M. (2010) Comparison of surgical and medical treatment of 49 postpartum mares with presumptive or confirmed uterine tears. Vet. Surg. 39, 254-60; DOI 10.1111/i.1532950X.2010.00645.x

Klohnen A. (2012) Evaluation of horses with signs of acute and chronic abdominal pain. In: Advances in Equine Laparoscopy, 1st ed., Ed.: Ragle C. A., Wiley-Blackwell, Oxford. 93-118. DOI 10.1002/9781118704875.ch9

Lee M., Hendrickson D. A. (2008) A review of equine standing laparoscopic ovariectomy. Equine Vet. Sci. 28 105-111; DOI 10.1016/i.jevs.2007.12.004

McNally T. P., Rodgerson D. H., Lu K. G. (2012) Infertility in a mare with a chronic uterine tear, diagnosis and successful standing hand-assisted laparoscopic repair. Equine Vet. Educ. 24, 439443; DOI 10.1111/j.2042-3292.2011.00308.x

Perkins N. R., Robertson J. T., Colon L. A. (1992) Uterine torsion and uterine tear in a mare. J. Am. Vet. Med. Assoc. 201, 92-94

Ragle C. A., Yiannikouris S., Tibary A. A., Fransson B. A. (2013) Use of a barbed suture for laparoscopic closure of the internal inguinal rings in a horse. J. Am. Vet. Med. Assoc. 242, 249-253; DOI 10.2460/javma.242.2.249

Schürmann C., Loose M., Failing K., Wehrend A. (2019) Retained placenta in mares - an analysis of 121 cases. Tierarztl. Praxis $G$ 47, 373-379; DOI 10.1055/a-1019-7345

Southwood L. L. (2013) Appendix C. Normal Ranges for Hematology and Palsma Chemistry and Conversion Table for Units. In: Practical Guide to Equine Colic (ed. 1); 339. Southwood L. L. (ed.). John Wiley \& Sons, Inc. DOI 10.1002/9781118704783

Sutter W. W., Hooper S., Embertson R. M., Frazer G. S. (2003) Diagnosis and surgical treatment of uterine lacerations in mares (33 cases). In: Proceedings of the Annual Meeting of the Association of Equine Practitioners. Vol 49, 357-359

Turner R. M. (2007) Post-Partum Problems: The Top Ten List. In: Proceedings of the Annual Meeting of the Association of Equine Practitioners. Vol 53. 305-319

Wheat J. D., Meagher D. M. (1972) Uterine torsion and rupture in mares. J. Am. Vet. Med. Assoc. 160, 881-884

Woodie B. (2019) Chapter 63: Uterus and Ovaries. In: Equine Surgery, ed. 5, 1083-1094. Auer J. A., Stick J. A. , Kümmerle J. M., Prange T.. Elsevier. St. Louis, Missouri 63043. DOI:10.1016/ B978-0-323-48420-6.00063-6. 